\title{
ANALISIS MANFAAT EKONOMI DI HULU DAS JENEBERANG PERIODE 2006-2026
}

\author{
Adelia Juli Kardika* \\ Pengelolaan Hutan, Politeknik Pertanian Negeri \\ Samarinda, Samarinda, KodePos 75131 \\ adeliajk@politanisamarinda.ac.id \\ *Corresponding author
}

\author{
Faradilla \\ Budidaya Tanaman Perkebunan, Politeknik Pertanian \\ Negeri Samarinda, Samarinda, KodePos 75131 \\ dillafara828@gmail.com
}

\begin{abstract}
Abstrak - Perubahan penggunaan lahan dalam dekade terakhir sangat cepat. Hal ini berdampak pada penurunan kualitas lingkungan. Padahal, hutan memiliki manfaat ekonomi, ekologi, dan sosial. Penilaian manfaat ekonomi suatu lahan dalam kurun waktu tertentu dapat dilakukan melalui analisis Net Present Value (NPV). Hulu DAS Jeneberang merupakan pemasok utama kebutuhan air bersih Kota Makassar dan Sungguminasa dan pengendali banjir. Penelitian ini bertujuan menghitung manfaat ekonomi penutupan/penggunaan lahan di hulu DAS Jeneberang yang meliputi sawah, pertanian lahan kering dan kebun menggunakan REDD Abacus di tahun 2006-2026. Metode yang digunakan dalam penelitian ini adalah ground check, pembagian kuisioner untuk menghitung manfaat ekonomi, dan melakukan skenario manfaat ekonomi dari tahun 20062026 menggunakan REDD ABACUS. nilai NPV pertanian lahan kering adalah nilai NPV terbesar dibandingkan dengan nilai NPV kebun dan nilai NPV sawah yaitu Rp 94.511.966,00. Hal ini menunjukkan bahwa penggunaan/penutupan lahan pertanian lahan kering memiliki nilai manfaat ekonomi jauh lebih besar dibandingkan yang lainnya. Nilai total biaya manfaat ekonomi dihitung dari tiga penutupan/penggunaan lahan yaitu sawah, pertanian lahan kering dan kebun. Dengan memperhatikan luasan ketiga penutupan/penggunaan lahan tersebut masyarakat mendapat nilai total biaya manfaat ekonomi sebesar Rp 23.056.324,00 per-Ha luasan yang elijibel (\$/(ha.tahun)) pada tahun 2010 dan diperkirakan akan meningkat menjadi Rp 119.235.425,00 per-Ha luasan yang elijibel
\end{abstract} (\$/(ha.tahun)) pada tahun 2026.

Kata Kunci- DAS, Nilai ekonomi, NPV (Net Present Value), REDD ABACUS, penggunaan lahan, penutupan lahan

\section{PENDAhuluan}

Deforestasi adalah perubahan secara permanen dari areal berhutan menjadi tidak berhutan yang diakibatkan oleh kegiatan manusia (Kementerian Kehutanan, 2009). Perubahan penggunaan lahan dalam dekade terakhir sangat cepat, terutama dari lahan hutan menjadi lahan untuk kepentingan bukan hutan. Laju deforestasi di Indonesia tahun 2019 mencapai 462.458,5 ha (Badan Pusat Statistik, 2020). Perubahan ini berdampak pada penurunan kualitas lingkungan. Berdasarkan hal ini praktek pengelolaan hutan secara lestari secara umum belum mencapai prinsip-prinsip pengelolaan hutan lestari, sehingga dapat mengancam kelangsungan manfaat ekonomi dan lingkungan. Padahal, hutan memiliki manfaat ekonomi, ekologi, dan sosial. Manfaat ekonomi hutan dalam menghasilkan kayu dan bukan kayu, manfaat ekologi hutan, seperti: fungsi hutan untuk mengendalikan erosi, memelihara kesuburan tanah, menjaga tata air, serta fungsi hutan dalam konservasi tanah dan air, dan manfaat sosial dalam menyediakan lapangan kerja. Penilaian manfaat ekonomi suatu lahan dalam kurun waktu tertentu dapat dilakukan melalui analisis Net Present Value (NPV).

Penutupan lahan lebih memiliki fungsi sebagai kawasan hutan lindung, hutan produksi, dan hutan konservasi, sedangkan lahan milik masyarakat lebih difungsikan sebagai lahan pertanian yang digunakan sebagai mata pencaharian untuk memperoleh pendapatan (Hindra, 2006). Perbedaan fungsi lahan akan mempengaruhi manajemen lahan dalam hal penentuan jenis vegetasi yang ditanam, kerapatan, serta perlu atau tidaknya perawatan dalam lahan (Hairiah et al., 2010). Pertimbangan ekonomi bagi pemilik lahan merupakan salah satu faktor penentu bagi pemilik lahan untuk mengambil keputusan terhadap pengelolaan lahannya.

Nilai manfaat ekonomi suatu lahan dalam memberikan pendapatan untuk perbaikan dalam aspek ekonomi menjadi hal yang penting bagi pemilik lahan dalam mengambil keputusan dalam menentukan manajemen lahan. Penilaian manfaat ekonomi dapat dihitung dengan NPV (Net Present Value) yang merupakan selisih antara pengeluaran (biaya investasi, biaya operasi, dan pemeliharaan) dan pemasukan yang telah didiskon dengan menggunakan social opportunity cost of capital sebagai diskon faktor (White et al., 2010). Nilai NPV tiap lahan akan berbeda tergantung lokasi pengembangannya. Hal tersebut dipengaruhi oleh harga pasar dan biaya yang dikeluarkan untuk tenaga kerja. Pehitungan NPV sangat bermanfaat didalam memberikan informasi ekonomi untuk menganalisis trade-off yang terjadi dalam aspek ekologi dan ekonomi. Upaya pengurangan emisi melalui peningkatan cadangan karbon dalam sistem biasanya diikuti oleh menurunnya keuntungan dari aspek ekonomi sehingga trade off antara upaya mempertahankan cadangan karbon dengan manfaat ekonomi yang didapat semakin tinggi 
Ruang lingkup penelitian ini adalah Daerah Aliran Sungai (DAS) yaitu tepatnya di Hulu DAS Jeneberang dengan fokus area penelitian pada Sub DAS Lengkese dan Sub DAS Malino. Sub DAS ini merupakan pemasok utama kebutuhan air bersih Kota Makassar dan Sungguminasa, pengendali banjir, penyedia air untuk persawahan, pembangkit listrik tenaga air (PLTA) sebesar serta fungsi waduk Bili-bili sebagai objek wisata.

Menyadari pentingnya keberadaan DAS Jeneberang, maka perlu dilakukan pengelolaan DAS yang baik dan terencana. Kabupaten Gowa merupakan daerah yang berdekatan dengan Kota Makassar, ibukota Provinsi Sulawesi Selatan dan termasuk kawasan MAMMINASATA (Makassar, Maros, Sungguminasa dan Takalar). Kawasan ini merupakan kawasan yang menjadi pusat aktivitas manusia dan pengembangan industri ke depan, yang diduga akan menghasilkan emisi gas rumah kaca yang tinggi (BPDAS JeneberangWalanae, 2003).

REDD Abacus adalah perangkat lunak yang dapat digunakan untuk (1) melakukan estimasi emisi dari perubahan penggunaan lahan dengan memperhatikan keragaman jenis tanah, elevasi, iklim, dan karakteristik biofisik lansekap lainnya; (2) melakukan analisa trade-off antara emisi dan keuntungan ekonomi (opportunity cost analysis), membuat kurva abatement cost, memprediksi emisi dan keuntungan ekonomi di masa yang akan datang ( Reference Emission Level (REL) projection) dan (3) melakukan simulasi scenario kegiatan mitigasi dan kebijakan pada unit perencanaan tertentu untuk pengurangan emisi dan melakukan analisa potensi opportunity cost-nya. Penelitian ini bertujuan menghitung manfaat ekonomi penutupan/penggunaan lahan di hulu DAS Jeneberang yang meliputi sawah, pertanian lahan kering dan kebun menggunakan REDD Abacus di tahun 2006-2026. Kegunaan dari penelitian ini dapat menjadi bahan pertimbangan dalam rangka mendukung pembangunan rendah emisi karbon pada hulu DAS Jeneberang.

\section{METODOLOGI}

Penelitian ini dilakukan di Hulu Daerah Aliran Sungai Jeneberang Provinsi Sulawesi Selatan yang secara geografis terletak antara 1190 32'30"-1190 57'00" Bujur Timur dan 50 4'00"-5 0 28'30" Lintang Selatan. Data penelitian yang digunakan dalam penelitian terdiri dari dua jenis yaitu data primer dan data sekunder. Data primer adalah data yang diperoleh melalui kegiatan pengamatan lapangan yaitu ground check (pengecekan hasil klasifikasi tutupan lahan menggunakan citra satelit dengan kondisi yang sebenarnya di lapangan) dan menganalisis kondisi sosial ekonomi penduduk dilakukan dengan pembagian kuisioner yang bertujuan untuk menghitung manfaat ekonomi pada sistem penggunaan lahan yang ada di Daerah Aliran Sungai (DAS) Hulu Jeneberang, dengan metode purpose sampling. Sedangkan data sekunder yang digunakan adalah data kepadatan penduduk. Prosedur analisis data yaitu:

\section{A. Menghitung Manfaat Ekonomi}

Manfaat ekonomi dari penutupan/penggunaan lahan (sawah, pertanian lahan kering, dan kebun) dianalisis menggunakan pendekatan nilai NPV yang diperoleh dari sistem penggunaan lahan tersebut. Net present value (NPV) adalah suatu indikator umum yang digunakan untuk menilai manfaat ekonomi pada kurun waktu tertentu. NPV merupakan akumulasi selisih antara pendapatan dan pengeluaran yang terdiskonto selama periode waktu tertentu. Perhitungan NPV mengikuti rumus sebagai berikut:

$$
\mathrm{NPV}=\sum_{t=0}^{t=n} \frac{\mathrm{B}_{\mathrm{t}}-\mathrm{C}_{\mathrm{t}}}{(1+\mathrm{i})^{\mathrm{t}}}
$$

Keterangan :

$$
\begin{aligned}
& \mathrm{B}_{\mathrm{t}}=\text { Pendapatan pada tahun } \mathrm{t} \\
& \mathrm{C}_{\mathrm{t}}=\text { Biaya pada tahun } \mathrm{t} \\
& \mathrm{t}=\text { Waktu dalam tahun } \mathrm{t} \\
& \mathrm{i}=\text { Tingkat suku bunga }(\%)
\end{aligned}
$$

Dari persamaan diatas, apabila nilai NPV diatas 0 (nol) dapat dikatakan memiliki nilai positif yang artinya sistem penggunaan lahan tersebut menguntungkan. Semakin tinggi nilainya (positif) maka semakin tinggi pula keuntungan yang didapat dalam sistem tersebut.

\section{B. Skenario nilai manfaat ekonomi dengan REDD ABACUS}

Penyusunan skenario nilai manfaat ekonomi dilakukan dengan memanfaatkan aplikasi REDD ABACUS. Dalam proses ini akan dilakukan analisis trade-off antara emisi dan keuntungan ekonomi (opportunity cost analysis), menghitung keuntungan ekonomi di masa yang akan datang (Reference Emission Level (REL) projection).

\section{HASIL DAN PEMBAHASAN}

Net present value $(N P V)$ adalah suatu indikator umum yang digunakan untuk untuk menilai manfaat ekonomi pada kurun waktu tertentu. NPV merupakan akumulasi selisih antara pendapatan dan pengeluaran yang terdiskonto selama periode waktu tertentu. Pada Tabel 1 dapat dilihat bahwa mata pencaharian masyarakat hulu DAS Jeneberang sebagai petani pertanian lahan kering sangat menguntungkan jika dibandingan dengan penggunaan lahan sawah dan kebun. Nilai ekonomi didapatkan dari pembagian kuisioner pada masyarakat.

Tabel 1. Nilai manfaat ekonomi pada hulu DAS Jeneberang

\begin{tabular}{|c|c|c|c|}
\hline Tahun & $\begin{array}{c}\text { Nilai NPV } \\
\text { Kebun }\end{array}$ & $\begin{array}{c}\text { Nilai NPV } \\
\text { Pertanian } \\
\text { LahanKering }\end{array}$ & $\begin{array}{c}\text { Nilai NPV } \\
\text { Sawah }\end{array}$ \\
\hline $\mathrm{T}-1$ & Rp 5.933.806 & Rp 23.049.645 & Rp 6.632.388 \\
$\mathrm{T}-2$ & Rp 6.154.899 & Rp 23.472.271 & Rp 6.724.273 \\
$\mathrm{T}-3$ & Rp 6.490.809 & Rp 23.827.207 & Rp 6.766.452 \\
$\mathrm{T}-4$ & Rp 6.681.616 & Rp 24.162.843 & Rp 6.806.338 \\
\hline Total & Rp 25.261.131 & Rp 94.511.966 & Rp 26.929.451 \\
\hline
\end{tabular}


Berdasarkan data Tabel 1, nilai NPV pertanian lahan kering adalah nilai NPV terbesar dibandingkan dengan nilai NPV kebun dan nilai NPV sawah yaitu Rp 94.511.966,00. Hal ini menunjukkan bahwa penggunaan/penutupan lahan pertanian lahan kering memiliki nilai manfaat ekonomi jauh lebih besar dibandingkan yang lainnya. Selain itu untuk penutupan/penggunaan lahan kebun, pertanian lahan kering dan sawah, kriteria kelayakan pada parameter NPV nya dapat dipenuhi karena perhitungan menunjukkan nilai NPV $>0$, yang artinya dapat memberikan keuntungan bersih sebesar Rp 25.261.131 untuk kebun, Rp 94.511.966 untuk pertanian lahan kering dan Rp 26.929.451 untuk sawah.
Meningkatnya emisi karbon di atmosfer akan memberikan sinyal bahaya bagi masyarakat karena akan mempercepat terjadinya pemanasan global yang berdampak terjadinya perubahan iklim. Oleh karena itu perlunya dilakukan penyusunan skenario dan simulasi untuk mengatasi ancaman tersebut. Berdasarkan hasil analisis skenario penutupan/penggunaan lahan dengan menggunakan REDD ABACUS maka diperoleh hasil pada skenario keempat (4 kali pengulangan) estimasi emisi dan nilai manfaat ekonominya mengalami peningkatan. Hasil total biaya manfaat ekonomi menggunakan aplikasi REDD ABACUS disajikan pada Tabel 2.

Tabel 2 Total biaya manfaat ekonomi pada hulu DAS Jeneberang

\begin{tabular}{|c|c|c|c|c|c|}
\hline $\begin{array}{c}\text { Iterasi } \\
\text { Periode -> }\end{array}$ & $\begin{array}{c}\text { Tahun 2006-2010 } \\
\text { (Rp) }\end{array}$ & $\begin{array}{c}\text { Tahun 2011-2014 } \\
\text { (Rp) }\end{array}$ & $\begin{array}{c}\text { Tahun 2015-2018 } \\
\text { (Rp) }\end{array}$ & $\begin{array}{c}\text { Tahun 2019-2022 } \\
\text { (Rp) }\end{array}$ & $\begin{array}{c}\text { Tahun } 2023-2026 \\
\text { (Rp) }\end{array}$ \\
\hline $\begin{array}{c}\text { Private - } \\
\text { Total Biaya- } \\
\text { Manfaat Per- } \\
\text { Ha Luasan } \\
\text { (\$/(ha.tahun)) }\end{array}$ & 23.056 .324 & 47.100 .947 & 71.145 .669 & 95.190 .494 & 119.235 .425 \\
\hline $\begin{array}{c}\text { Private - } \\
\text { Total Biaya- } \\
\text { Manfaat Per- } \\
\text { Ha Luasan } \\
\text { yang Elijibel } \\
(\$ /(\text { ha.tahun }))\end{array}$ & 23.056 .324 & 47.100 .947 & 71.145 .669 & 95.190 .494 & 119.235 .425 \\
\hline $\begin{array}{c}\text { Private - } \\
\text { Total Biaya- } \\
\text { Manfaat } \\
\text { (\$/tahun) }\end{array}$ & 886.521 .416 .149 & 1.811 .043 .170 .120 & 2.735.568.762.571 & 3.660 .098 .304 .801 & 4.584.631.905.483 \\
\hline $\begin{array}{c}\text { Private - } \\
\text { Total Biaya- } \\
\text { Manfaat yang } \\
\text { Elijibel } \\
\text { (\$/tahun) }\end{array}$ & 886.521 .416 .149 & 1.811 .043 .170 .120 & 2.735 .568 .762 .571 & 3.660 .098 .304 .801 & 4.584 .631 .905 .483 \\
\hline
\end{tabular}

Berdasarkan hasil skenario menggunakan REDD ABACUS menunjukkan bahwa total biaya manfaat perHa luasan di tahun 2006-2010 sebesar Rp 23.056.324,00. Sedangkan untuk untuk tahun 2011-2014 total biaya manfaat perHa luasannya yaitu $\mathrm{Rp} 47.100 .947,00$, dan terus meningkat pada skenario di tahun 2023-2026.

Total biaya manfaat yang elijibel berdasarkan skenario dengan REDD ABACUS tahun 2006-2010 yaitu Rp 886.521.416.149,00 dan terus meningkat hingga skenario di tahun 2023-2036 sebesar Rp 4.584.631.905.483. Bila dibandingkan dengan skenario di tahun 2006-2010, skenario di tahun 2023-2036 memberikan nilai manfaat ekonomi yang jauh lebih besar namun dengan peningkatan penyerapan karbon di masing-masing penutupan/penggunaan lahan sehingga nantinya dapat mengurangi emisi, maka skenario nilai manfaat ekonomi dapat tercapai.

\section{KESIMPULAN}

Nilai total biaya manfaat ekonomi dihitung dari tiga penutupan/penggunaan lahan yaitu sawah, pertanian lahan kering dan kebun. Dengan memperhatikan luasan ketigapenutupan/penggunaan lahan tersebut masyarakat mendapat nilai total biaya manfaat ekonomi sebesar Rp 23.056.324,00 per-Ha luasan yang elijibel (\$/(ha.tahun)) pada tahun 2010 dan diperkirakan akan meningkat menjadi Rp 119.235.425,00 per-Ha luasan yang elijibel (\$/(ha.tahun)) pada tahun 2026.

\section{DAFTAR PUSTAKA}

Badan Pusat Statistik. (2020). Angka Deforestasi Netto Indonesia di Dalam dan di Luar Kawasan Hutan Tahun 2013-2019 (Ha/Thn). Jakarta: Badan Pusat Statistik. 
(BPDAS Jeneberang-Walanae) Balai Pengelolaan Daerah Aliran Sungai Jeneberang Walanae. (2003). Penyusunan Rencana Teknik Lapangan Rehabilitasi Lahan dan Konservasi Tanah Daerah Aliran Sungai (DAS) Jeneberang Propinsi Sulawesi Selatan. Makassar: BPDAS JeneberangWalanae.

Billy H. (2006). Potensi dan Kelembagaan Hutan Rakyat. Prosiding Seminar Hasil Litbang Hasil Hutan, Bogor: Pusat Penelitian dan Pengembangan Hasil Hutan. $\mathrm{h}$ 14-20.

Hairiah, K., Hamid, A., Widianto, Kurniawan, S., Wicaksono, K. S., Sari, R. R., Lestariningsih, I. D.,

Lestari, N. D. (2010). Potensi kawasan Tahura R.Soerjo sebagai penambat dan penyimpan karbon. Laporan akhir kerjasama penelitian antara Balitbang Provinsi Jatim dengan Fakultas Pertanian, Universitas Brawijaya.

Kementerian Kehutanan. (2009). Peraturan Menteri Kehutanan Indonesia Nomor 30 Tahun 2009 tentang Tata Cara Pengurangan Emisi dari Deforestasi dan Degradasi Hutan (REDD). Jakarta: Kementerian Kehutanan.

White, D., and Minang, P. (2011). Estimating the opportunity costs of REDD+: A training manual, version 1.3. Washington, DC: World Bank Institute. 